\title{
Metabolic and body composition changes in first year following traumatic amputation
}

\author{
Carly S. Eckard, MS, RD; ${ }^{1-2}$ Alison L. Pruziner, PT, DPT, ATC; ${ }^{3-5 *}$ Allison D. Sanchez, MS, RD; ${ }^{1,6-7}$ Anne M. \\ Andrews, $\mathbf{P h D}, \mathbf{R D}^{\mathbf{1 , 5 , 8}}$ \\ ${ }^{1}$ Nutrition Care Directorate, Walter Reed Army Medical Center, Washington, DC; ${ }^{2}$ U.S. Army Health Center, Vicenza, \\ Italy; ${ }^{3}$ Department of Orthopedics and Rehabilitation, Walter Reed Army Medical Center, Washington, DC; \\ ${ }^{4}$ Department of Rehabilitation, Walter Reed National Military Medical Center, Bethesda, MD; ${ }^{5}$ Department of \\ Defense-Department of Veterans Affairs Extremity Trauma and Amputation Center of Excellence, Washington, DC; \\ ${ }^{6}$ U.S. Military-Baylor University Graduate Program in Nutrition, San Antonio, TX; ${ }^{7}$ William Beaumont Army Medical \\ Center, Ft. Bliss, TX; ${ }^{8}$ Office of the Surgeon General, Falls Church, VA
}

\begin{abstract}
Body composition and metabolism may change considerably after traumatic amputation because of muscle atrophy and an increase in adiposity. The purpose of this study was to quantify changes in weight, body composition, and metabolic rate during the first year following traumatic amputation in military servicemembers. Servicemembers without amputation were included for comparison. Participants were measured within the first 12 wk after amputation (baseline) and at 6, 9, and 12 mo after amputation. Muscle mass, fat mass, weight, and metabolic rate were measured at each time point. There was a significant increase in weight and body mass index in the unilateral group between baseline and all follow-up visits $(p<$ 0.01 ). Over the 12 mo period, total fat mass and trunk fat mass increased in both unilateral and bilateral groups; however, these changes were not statistically significant over time. Muscle mass increased in both the unilateral and bilateral groups despite percent of lean mass decreasing. No changes in resting metabolism or walking energy expenditure were observed in any group. The results of this study conclude that weight significantly increased because of an increase in both fat mass and muscle mass in the first year following unilateral and bilateral amputation.
\end{abstract}

Key words: amputation, atrophy, body composition, body mass index, DXA, fat mass, metabolism, muscle mass, trauma, unilateral, weight gain.

\section{INTRODUCTION}

From 2001 to July 2011, more than 1,200 U.S. military servicemembers experienced major lower-limb amputations while engaged in Operation Iraqi Freedom, Operation Enduring Freedom, and Operation New Dawn [1]. The injury itself, as well as muscle atrophy, leads to loss of lean body mass [2]. However, metabolic changes during physiologic stress, medications, and change in energy intake may lead to increased fat deposition and further loss of lean body mass [3-4]. Understanding metabolic and body composition changes during the first year after amputation is essential to design and tailor treatment plans, which may improve anthropometric and

Abbreviations: $\mathrm{BMI}=$ body mass index, DXA $=$ dual-energy $\mathrm{X}$-ray absorptiometry, $\mathrm{VO}_{2}=$ oxygen consumption, WRAMC = Walter Reed Army Medical Center.

*Address all correspondence to Alison L. Pruziner, PT, DPT, ATC; DOD-VA Extremity Trauma and Amputation Center of Excellence, Walter Reed National Military Medical Center, America Building (Bldg 19), Rm B315, 8901 Rockville Pike, Bethesda, MD 20889; 301-295-8527.

Email: alison.l.pruziner.civ@mail.mil

http://dx.doi.org/10.1682/JRRD.2014.02.0044 
functional outcomes and build awareness for the individual with amputation.

There are limited data on body composition changes in the first year after traumatic amputation, especially in military populations. Muscle atrophy is commonly seen in the amputated limb [5-9], which may be due to decreased use of the muscle tissue [4], as well as reduced muscle fiber size [5]. The level of amputation is a significant factor in the severity of muscle atrophy $[7,10]$. Additionally, diminished muscle strength typically occurs after amputation [4,10-13], which influences the function of the residual limb and prosthesis [5] and complicates the ability to perform daily activities [12].

Loss of muscle mass jeopardizes healing by promoting catabolism [14]. Acute loss of only 5 percent muscle mass results in organ dysfunction, whereas an acute 20 percent loss of muscle mass may result in organ failure and death [15]. Loss of muscle mass may also affect wound healing, ability to participate in therapy, and length of recovery. However, it is unclear whether the initial loss from amputation or accumulated losses from muscle atrophy over time have a greater effect on overall health and rehabilitation. Consequently, it is of utmost importance to prevent muscle atrophy through early interventions [12].

Although it is common for muscle mass to decrease after amputation, fat mass may increase [6,16]. In previous research, thigh fat percent was significantly higher in the amputated thigh following transfemoral and transtibial amputations compared with the intact limb [6]. Also, increases in subcutaneous fat after lower-limb amputation appear to be the main cause of obesity progression [16]. Excess fat mass may affect the fit of a prosthesis and may additionally impinge on mobility [16-17].

Metabolic changes during critical illness and trauma are well understood in the initial stress response and wound healing phases. In the initial stress response, increases in basal metabolic rate and protein catabolism are the hallmark effects of the hormonal response to physiologic stress [18-20]. During inflammation and wound healing, energy needs may increase by 30 to 50 percent [21]. In addition, prolonged protein catabolism can lead to significant losses of lean body mass, primarily from skeletal muscle [20]. Metabolic rate typically returns to a preinjury level as wound healing progresses, but metabolic changes in individuals with amputations undergoing long-term rehabilitation and multiple surgical interventions has not been previously studied [20].
Previous research on body composition in individuals with amputations may not be applicable to today's population of Active Duty servicemembers recovering from amputations. Much of the existing data on changes in body composition are based on nontraumatic amputations that occurred from dysvascular causes and include a broad age spectrum $[4-5,10-11,16]$. The purpose of this research study was to quantify weight, muscle mass, fat mass, and metabolic changes during the first year following traumatic amputation in servicemembers. We hypothesized that muscle mass would decrease and fat mass would increase in the first year after amputation. In addition, we hypothesized that metabolic rate would decrease in the first 6 mo after amputation, followed by no change from 6 to 12 mo.

\section{METHODS}

\section{Design}

In this case-control, repeated-measures study, data on body composition and metabolic changes were collected from participants with and without unilateral and bilateral lower-limb traumatic amputation. The study was approved by the Institutional Review Board at Walter Reed Army Medical Center (WRAMC) in Washington, DC. All participants provided written, informed consent according to the guidelines of the Department of Clinical Investigation at WRAMC.

\section{Participants}

Between 2008 and 2011, U.S. military servicemembers with unilateral and bilateral lower-limb traumatic amputation and age- and sex-matched controls participated in this research study. The participants with amputation were recruited by convenience sampling within 12 wk after amputation upon admission to the medical center. Military servicemembers without amputation were recruited through word of mouth. Female control participants were recruited, as needed, to match females with amputations in a 1:1 ratio.

Inclusion criteria included male and female Active Duty servicemembers, aged $18 \mathrm{yr}$ and older. Servicemembers with amputation were included if they had lowerlimb amputation as a result of trauma. Exclusion criteria included pregnancy, nontrauma-related amputation (i.e., vascular or osteosarcoma amputation), upper-limb amputation, and traumatic brain injury severe enough to affect the ability to follow commands or provide consent. 


\section{Procedure}

The study included four scheduled visits for all participants: baseline, $6 \mathrm{mo}, 9 \mathrm{mo}$, and 12 mo following amputation. Baseline visits for unilateral and bilateral participants were conducted within 12 wk after amputation. Follow-up visits occurred 6, 9, and 12 mo after amputation for unilateral and bilateral participants and after baseline visit for control participants. At the initial visit, participants provided background information such as birth date, race, height and weight before amputation, date of injury, and date and level of amputation. At all visits, weight, body composition, heart rate, and resting metabolic rate were assessed. Additionally, heart rate and energy expenditure during ambulation were measured at 6, 9, and 12 mo.

\section{Instrumentation}

Anthropometric measurements included height, weight, and body mass index (BMI). Stated height from the last official military measurement was obtained from each participant and recorded to the nearest half inch [22-24]. Weight was measured to the nearest $0.1 \mathrm{~kg}$ using a digital scale (Seca; Hamburg, Germany) in a standing position. Weight was measured without prosthesis, if possible, or the prosthesis was weighed separately and subtracted from the total weight. Pre-amputation weight was self-reported. Assumed weight at time of amputation was calculated using the following equation: $\mathrm{AW}=\mathrm{PW}-(\mathrm{PW} \times \mathrm{P})$, where AW is the assumed weight at time of amputation, $\mathrm{PW}$ is the pre-amputation weight, and $\mathrm{P}$ represents the proportion of total body weight represented by the missing limb segments [25]. The proportion of the remaining segment, thigh or shank, was estimated by measuring the lengths of the residual limb femur or tibia, respectively, on the dual-energy X-ray absorptiometry (DXA) scan and comparing it with the intact bone. For bilateral participants, self-reported height prior to amputation was used to estimate thigh and/or shank length using previously reported average percentages of height for males.

Adjusted weight was calculated using the following equation: $\mathrm{Wt}_{\mathrm{E}}=\mathrm{Wt}_{0} /(1-\mathrm{P})$, where $\mathrm{Wt}_{\mathrm{E}}$ is an estimate of the total body weight, $\mathrm{Wt}_{0}$ is the observed body weight, and $\mathrm{P}$ again represents the proportion of total body weight represented by the missing limb segments [26]. BMI was calculated using the standard equation: weight (kilograms)/height (meters squared). Adjusted weight was used to calculate BMI for participants with amputations.
Whole body composition (muscle mass and fat mass) was measured using a linear fan beam DXA (Windows XP version software, Hologic, DISCOVERY-Wi; Bedford, Massachusetts). The scan measurements and analyses were conducted following standard procedures, to include the wear of lightweight clothing. Calibration took place in accordance with manufacturer specifications. Scans were performed by trained research personnel, and every scan was reviewed for quality control by the laboratory director. The specific regions evaluated and used in the statistical analyses were trunk fat mass, trunk fat percent, total fat mass, total fat percent, and total muscle mass. DXA scans are valid and reliable for assessing body composition changes [27-29].

Oxygen uptake, heart rate, and energy expenditure were measured using the Oxycon Mobile metabolic analysis system (Viasys; Yorba Linda, California). Oxycon Mobile accuracy for both carbon dioxide output and oxygen consumption $\left(\mathrm{VO}_{2}\right)$ is within 3 percent and validated against the Douglas Bag method [30-31]. $\mathrm{VO}_{2}$ and heart rate were measured on a breath by breath cycle using the Oxycon Mobile metabolic analysis system and a Polar heart rate chest strap (Polar Electro Inc; Lake Success, New York). Data from the Oxycon Mobile unit were collected continuously. For the walking metabolic analysis, the following data points were evaluated: (1) the rest period of 5 min prior to walking to identify resting, baseline metabolic levels and heart rate; (2) after approximately 10 min of walking at a self-selected pace on an indoor track to capture steady-state $\mathrm{VO}_{2}$ and heart rate; and (3) 5 min after the bout of walking has been completed, as the participant returned to baseline. Walking time for the collections was based on when the participant was able to achieve steady-state $\mathrm{VO}_{2}$ and maintain it for at least $2 \mathrm{~min}$. $\mathrm{VO}_{2}$ values were observed in real-time, so participants were stopped prior to the $10 \mathrm{~min}$ period if a 2 min period of steady-state consumption was captured prior to this time.

\section{Data Analysis}

Descriptive statistics were generated using PASW Statistics 18 (IBM Corporation; Armonk, New York). The estimated marginal mean was chosen as the measure of central tendency to adjust for unequal group size with missing data. Generalized estimating equations were used to analyze changes over time in body composition and metabolism. Analyses included GROUP (control, unilateral, bilateral) and VISIT (1, 2, 3, 4) as main effects 
and the interaction GROUP $\times$ VISIT. Control participants were included in this study to demonstrate normal variations in body composition and metabolism at the time in question. Pairwise comparisons were completed using Bonferroni correction for multiple comparisons. A sample size of 24 was needed to yield statistical power of greater than 80 percent. Effect size was set at 1.5 to detect a significant difference in body fat percent. Differences were considered significant at $p<0.05$.

\section{RESULTS}

Forty-nine participants enrolled in this study (20 unilateral, 14 bilateral, and 15 control). The 31 participants (10 unilateral, 10 bilateral, and 11 control) who completed at least two visits were included in data analyses. One subject had a delayed amputation and was excluded from analyses when it was discovered that between his injury and amputation his weight increased nearly $45 \mathrm{~kg}$. One female, unilateral participant was lost to follow-up; thus, sex-matched control data were also excluded from analysis. The remaining 16 participants were lost to follow-up or moved out of the area and could not complete study visits. Physical characteristics of all participants are listed in Table 1. There were no significant differences between groups at baseline.

Adjusted weight and BMI changes for all participants are listed in Table 2. Body composition changes for all participants are listed in Table 3. Weight, adjusted weight, BMI, total fat mass, total fat percent, trunk fat percent, and total lean mass all changed significantly by visit for all participants combined ( $p<0.01$ ). There was a significant weight gain in the unilateral group from baseline to 12 mo of $7.4 \mathrm{~kg}(p=0.001)$. There was a significant increase in adjusted weight of $9.4 \mathrm{~kg}(p=0.01)$ from baseline to 9 mo in the bilateral group.

Total fat mass peaked at 9 mo following amputation for the unilateral group, with an increase of $3.6 \mathrm{~kg}$ from baseline $(p=0.02)$. Total lean mass also increased significantly at 9 mo with a change of $3.6 \mathrm{~kg}$ from baseline $(p=$ 0.002). No further change was observed between 9 and 12 mo. No significant changes were observed in weight, BMI, or total body fat for the control group.

Metabolic changes, heart rate, and walking speed for all participants are listed in Table 4. Resting energy expenditure, resting heart rate, walking heart rate, and walking speed changed significantly by visit for all participants combined $(p<0.05)$. Resting heart rate, walking energy expenditure, walking heart rate, and walking speed changed significantly by group across visits $(p<0.05)$. The control group displayed significantly lower resting heart rates and walking energy expenditure than the bilateral group ( $p=0.007$ ), but there was no difference between the control group and unilateral group $(p=0.21)$ or between the amputation groups $(p>0.99)$. Walking heart rate and walking speed were significantly different between the bilateral group and both the control and unilateral group ( $p \leq 0.001$ ), but there was no difference between the control and unilateral groups $(p=0.08)$. There were no changes in resting energy expenditure between

Table 1.

Participant characteristics.

\begin{tabular}{|c|c|c|c|}
\hline Characteristic & Control $(n=11)$ & Unilateral $(n=10)$ & Bilateral $(n=10)$ \\
\hline Age (yr) ${ }^{*}$ & $28.6 \pm 4.1(21-34)$ & $23.1 \pm 2.8(20-29)$ & $24.4 \pm 3.5(20-31)$ \\
\hline \multicolumn{4}{|l|}{ Race } \\
\hline White & 7 & 9 & 9 \\
\hline Black & 1 & 1 & 0 \\
\hline Hispanic & 2 & 0 & 1 \\
\hline Asian/Pacific Islander & 1 & 0 & 0 \\
\hline $\mathrm{TF}$ & N/A & 3 & 0 \\
\hline $\mathrm{TF} / \mathrm{TF}$ & N/A & 0 & 8 \\
\hline $\mathrm{TT} / \mathrm{TF}$ & N/A & 0 & 2 \\
\hline Time Since Amputation (wk) ${ }^{*}$ & N/A & $9.0 \pm 3.7(2.9-13.3)$ & $9.1 \pm 3.5(4.3-14.6)$ \\
\hline
\end{tabular}

${ }^{*}$ Mean \pm standard deviation (range).

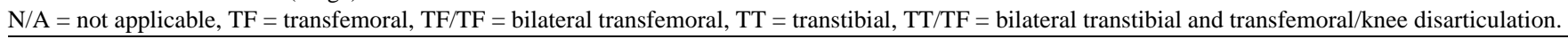


Table 2.

Weight and body mass index (BMI) changes over first 12 mo after amputation.

\begin{tabular}{|c|c|c|c|}
\hline Group & Height (cm) & Weight or Adjusted Weight (kg)* & BMI $\left(\mathrm{kg} / \mathrm{m}^{2}\right)^{*}$ \\
\hline Control $(n=11)$ & $178.3 \pm 3.7$ & & \\
\hline Baseline & & $86.4 \pm 4.0$ & $27.3 \pm 1.4$ \\
\hline $6 \mathrm{mo}$ & & $87.0 \pm 4.1$ & $27.4 \pm 1.4$ \\
\hline 9 mo & & $88.0 \pm 4.1$ & $27.7 \pm 1.4$ \\
\hline 12 mo & & $87.4 \pm 3.9$ & $27.6 \pm 1.4$ \\
\hline Unilateral $(n=10)$ & $177.8 \pm 4.8$ & & \\
\hline $6 \mathrm{mo}$ & & $85.1 \pm 3.6^{\ddagger}$ & $27.3 \pm 1.3^{\ddagger}$ \\
\hline $9 \mathrm{mo}$ & & $86.3 \pm 3.0^{\ddagger}$ & $27.7 \pm 1.1^{\ddagger}$ \\
\hline $12 \mathrm{mo}$ & & $85.1 \pm 3.6^{\ddagger}$ & $27.2 \pm 1.3^{\ddagger}$ \\
\hline Bilateral $(n=10)$ & $180.3 \pm 3.7$ & & \\
\hline Pre-Injury $^{\dagger}$ & & $81.1 \pm 6.5$ & $25.0 \pm 2.1$ \\
\hline $12 \mathrm{mo}$ & & $91.2 \pm 6.0$ & $28.2 \pm 1.6$ \\
\hline \multicolumn{4}{|c|}{$\begin{array}{l}\text { Note: Date are estimated marginal mean } \pm \text { standard error; weight an } \\
\text { * Significant difference VISIT main effect for all subjects, } p<0.01 \text {. } \\
{ }^{\dagger} \text { Pre-injury weight is self-reported. } \\
{ }^{\ddagger} \text { Different from baseline, } p<0.05 \text {. }\end{array}$} \\
\hline
\end{tabular}

Table 3.

Body composition changes over first 12 mo after amputation.

\begin{tabular}{|c|c|c|c|c|c|c|}
\hline Group & $\begin{array}{c}\text { Total Fat Mass } \\
\text { (kg) }{ }^{*}\end{array}$ & $\begin{array}{l}\text { Total Fat } \\
\text { Percent }\end{array}$ & $\begin{array}{c}\text { Trunk Fat Mass } \\
\text { (kg) }\end{array}$ & $\begin{array}{l}\text { Trunk Fat } \\
\text { Percent }\end{array}$ & $\begin{array}{c}\text { Total Lean Mass } \\
(\mathrm{kg})^{*}\end{array}$ & $\begin{array}{c}\text { Total Lean } \\
\text { Percent }\end{array}$ \\
\hline \multicolumn{7}{|c|}{ Control $(n=11)$} \\
\hline Baseline & $17.6 \pm 2.7$ & $19.6 \pm 2.3$ & $9.4 \pm 1.7$ & $20.9 \pm 2.6$ & $64.7 \pm 2.0$ & $76.6 \pm 2.1$ \\
\hline $9 \mathrm{mo}$ & $18.1 \pm 2.9$ & $19.9 \pm 2.4$ & $9.4 \pm 1.6^{\dagger}$ & $21.1 \pm 2.7$ & $65.5 \pm 1.9$ & $76.4 \pm 2.2$ \\
\hline $2 \mathrm{mo}$ & $18.9 \pm 3.2$ & $20.6 \pm 2.5$ & $10.7 \pm 2.2$ & $22.4 \pm 3.1$ & $65.1 \pm 1.7$ & $75.7 \pm 2.3$ \\
\hline $6 \mathrm{mo}$ & $16.6 \pm 1.4$ & $21.1 \pm 1.5$ & $8.1 \pm 0.9$ & $20.1 \pm 1.5$ & $58.9 \pm 2.4$ & $75.3 \pm 1.5$ \\
\hline $9 \mathrm{mo}$ & $17.5 \pm 1.4^{\dagger}$ & $22.0 \pm 1.6$ & $9.2 \pm 0.9^{\ddagger}$ & $21.6 \pm 1.6$ & $59.2 \pm 2.2^{\ddagger}$ & $77.6 \pm 3.3$ \\
\hline $12 \mathrm{mo}$ & $16.5 \pm 1.7$ & $20.9 \pm 1.9$ & $8.2 \pm 1.0$ & $20.2 \pm 2.0$ & $59.2 \pm 2.2^{\ddagger}$ & $75.7 \pm 1.8$ \\
\hline \multicolumn{7}{|c|}{ Bilateral $(n=10)$} \\
\hline Baseline & $11.6 \pm 1.0$ & $18.4 \pm 1.1$ & $9.9 \pm 3.2$ & $17.2 \pm 1.3$ & $48.4 \pm 1.0$ & $77.9 \pm 1.0$ \\
\hline
\end{tabular}

visits for any group. Resting heart rate, in the unilateral group, decreased significantly from baseline at 6 mo $(p=$ $0.03)$ and 12 mo $(p<0.001)$. There were no significant changes in resting heart rate in the bilateral group. However, walking heart rate increased significantly between 6 and 9 mo $(p=0.007)$ and decreased significantly 
JRRD, Volume 52, Number 5, 2015

Table 4.

Metabolic changes over first 12 mo after amputation.

\begin{tabular}{|c|c|c|c|c|c|}
\hline Group & $\begin{array}{l}\text { REE } \\
\text { (kcal) }\end{array}$ & $\begin{array}{l}\text { Resting HR } \\
\text { (bpm) }^{* \dagger}\end{array}$ & $\begin{array}{c}\text { Walking EE } \\
\text { (kcal) }^{\dagger}\end{array}$ & 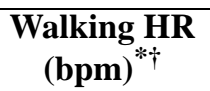 & $\begin{array}{l}\text { Walking Speed } \\
(\mathrm{m} / \mathrm{s})^{* \dagger}\end{array}$ \\
\hline \multicolumn{6}{|l|}{ Control $(n=11)$} \\
\hline Baseline & $2,176 \pm 118$ & $68 \pm 3$ & N/A & N/A & N/A \\
\hline $6 \mathrm{mo}$ & $1,984 \pm 68$ & $66 \pm 3$ & $6,388 \pm 427$ & $86 \pm 4$ & $1.20 \pm 0.16$ \\
\hline $9 \mathrm{mo}$ & $2,195 \pm 169$ & $66 \pm 4$ & $6,726 \pm 482$ & $86 \pm 4$ & $1.26 \pm 0.17$ \\
\hline $12 \mathrm{mo}$ & $2,350 \pm 195$ & $65 \pm 7$ & $6,881 \pm 613$ & $84 \pm 5$ & $1.38 \pm 0.29$ \\
\hline \multicolumn{6}{|c|}{ Unilateral $(n=10)$} \\
\hline Baseline & $2,400 \pm 193$ & $87 \pm 4$ & N/A & N/A & N/A \\
\hline $6 \mathrm{mo}$ & $2,355 \pm 86$ & $75 \pm 3^{\ddagger}$ & $7,810 \pm 587$ & $99 \pm 3$ & $1.05 \pm 0.25$ \\
\hline $9 \mathrm{mo}$ & $2,441 \pm 144$ & $74 \pm 4$ & $7,295 \pm 910$ & $94 \pm 6$ & $1.10 \pm 0.43$ \\
\hline $12 \mathrm{mo}$ & $2,581 \pm 152$ & $72 \pm 3^{\ddagger}$ & $8,348 \pm 436$ & $99 \pm 9$ & $1.11 \pm 0.20$ \\
\hline \multicolumn{6}{|l|}{ Bilateral $(n=10)$} \\
\hline Baseline & $2,356 \pm 58$ & $94 \pm 5$ & N/A & N/A & N/A \\
\hline $6 \mathrm{mo}$ & $2,036 \pm 192$ & $81 \pm 8$ & $7,212 \pm 607$ & $117 \pm 10$ & $0.56 \pm 0.18$ \\
\hline 9 mo & $2,267 \pm 100$ & $91 \pm 6$ & $9,156 \pm 822$ & $148 \pm 8^{\S}$ & $0.80 \pm 0.01^{\S}$ \\
\hline $12 \mathrm{mo}$ & $2,529 \pm 169$ & $84 \pm 4$ & $8,673 \pm 459$ & $121 \pm 7^{\mathbb{\Upsilon}}$ & $0.99 \pm 0.52^{q}$ \\
\hline
\end{tabular}

Note: Data are estimated marginal mean \pm standard error. Walking EE and HR not measured at baseline visit.

*Significant difference VISIT main effect for all subjects, $p<0.05$.

${ }^{\dagger}$ Significant difference GROUP main effect for all subjects, $p<0.05$.

${ }^{\ddagger}$ Different from baseline, $p<0.05$.

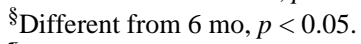

"Different from 9 mo, $p<0.01$.

bpm = beats per minute, $\mathrm{EE}$ = energy expenditure, $\mathrm{HR}$ = heart rate, $\mathrm{N} / \mathrm{A}=$ not applicable, $\mathrm{REE}$ = resting energy expenditure.

between 9 and 12 mo $(p=0.002)$ in this group. No significant changes in walking heart rate were observed in the unilateral group. There were no significant changes in walking energy expenditure for any group. As observed in the body composition measures, control group participants did not significantly change their resting or walking energy expenditure or heart rate across the year. Walking speed was significantly higher in the control and unilateral groups, across all visits, than in the bilateral group $(p<$ $0.001)$. Walking speed increased significantly in the bilateral group from 6 mo to 9 mo $(p<0.001)$ and from 9 mo to 12 mo $(p<0.001)$. No significant changes in walking speed were observed in the control or unilateral groups.

\section{DISCUSSION}

To our knowledge, this study is the first to assess and quantify body composition and metabolic changes during the first year after amputation. As expected, weight increased in both unilateral and bilateral groups. Contrary to our hypothesis, fat mass did not significantly increase over the year observational period, and a statistically sig- nificant increase in lean mass was observed in the unilateral group; however, lean mass percent did not parallel these changes. Percent lean mass did not increase, likely because of overall weight gain and increases in fat mass from baseline to 9 mo in the unilateral group. Additionally, no change was observed in resting metabolic rate, differing from our original hypothesis.

The significant increase in weight and lean mass between baseline and 12 mo postamputation may represent healing and successful rehabilitation. Both study groups with amputation participated in regular therapy, which typically consisted of at least $1 \mathrm{~h}$ of physical therapy and $1 \mathrm{~h}$ of occupational therapy $5 \mathrm{~d} / \mathrm{wk}$; however, overall time in therapy was not tracked during the study period. Research demonstrates that even a moderate amount of resistance exercises performed every few days is sufficient to counteract muscle mass loss [32]. Several previous studies report loss of lean body mass following amputation [4-8,11-12]. In a recent study, Sherk et al. found significantly decreased muscle mass $(p<0.01)$ in the amputated limb compared with the intact limb in 12 participants with unilateral amputation [6]. Additionally, in a study of 10 participants with unilateral amputation, Renström et al. identified atrophy in 
8 of 10 amputated limbs and in 7 of 9 intact limbs [5]. It is important to note that the aforementioned studies occurred between 2 and $15 \mathrm{yr}$ after many of the participants' amputations and the mean age of participants was $50 \mathrm{yr}$, which may make the results less comparable to our study.

Significant increase in fat mass occurred in the first 9 mo postamputation in the unilateral group. Additionally, there was a clinically significant, but not statistically significant, weight gain of $14.5 \mathrm{~kg}$ from baseline to 12 mo in the bilateral group. Increases in fat mass have been noted in previous research of individuals with amputations. In a long-term follow-up study of 327 individuals with bilateral traumatic amputation, Shahriar et al. observed abdominal obesity in 82.5 percent of the study sample [33]. Despite the lack of significant increases of total fat and trunk fat in both the unilateral and bilateral groups, there may be clinically significant changes related to total fat percent and trunk fat. According to Gallagher et al., normal body fat for males aged 20 to $39 \mathrm{yr}$ is between 8.0 and 19.9 percent [34]. At 12 mo postamputation, total body fat was equal to $20.9 \pm$ 1.9 percent and $22.5 \pm 3.0$ percent in the unilateral and bilateral groups, respectively. Based on these results, both groups would be categorized as high body fat or overweight. In addition, significant changes in BMI were only noted in the unilateral group, but both groups changed from normal BMI (18.5-24.9) at baseline to overweight (25.0-29.9) at 12 mo postamputation [34]. Furthermore, both groups exceeded their pre-injury BMI by 6 mo postamputation.

Our results may be clinically significant because of long-term risks of metabolic syndrome and cardiovascular disease caused by excess adiposity [16,35]. Ito et al. concluded that trunk fat mass of $\geq 8 \mathrm{~kg}$ for males and $\geq 9 \mathrm{~kg}$ for females were the cut-off points to detect cardiovascular risk factors [36]. Accordingly, the results of our study population with amputation, which indicated $8.2 \mathrm{~kg}$ (unilateral) and $10.8 \mathrm{~kg}$ (bilateral) of trunk fat mass at $12 \mathrm{mo}$ postamputation, exceed these values. In addition to future health risk, it is critical to moderate fat mass gain after amputation, considering that excess body fat leads to poor performance both physically and physiologically and may affect fit and function of prostheses [17,37-39]. Possible explanations for the notable increase in fat mass may be related to increased medications such as pain and psychotropic medications; unhealthy eating habits, which included increased calories, low-nutrient dense foods, and alcohol intake; changes in physical activity from before the injury; lack of nutrition education; or psychological issues [32,40]. However, data were not collected in this study to address these concerns. All participants received standard of care nutrition assessments and interventions, as needed, during inpatient hospitalization, but additional study-specific outpatient nutrition education was not included as part of this study since the intent was to observe body composition changes.

No change in resting metabolic rate was observed in either study group or the control group. As described in previous research, initial increases in metabolic rate in response to inflammation and physiological stress taper to pre-injury levels within 2 wk of injury or surgery [20]. In this study population, baseline data were collected within 12 wk of amputation, likely after return of the metabolic rate to normal levels. In addition, lean body mass was maintained in both the unilateral and bilateral group, limiting the effect of changes in body composition on metabolism. A significant decrease was observed in the resting heart rate for the unilateral group at the 6 and 9 mo time points compared with baseline. Walking heart rate significantly increased for the bilateral group between the 6 and 9 mo visits, likely because of the significant increase in walking speed between these visits. Interestingly, there was a significant decrease in walking heart rate in this group between the 9 and 12 mo visits, despite a significant increase in walking speed likely indicating improvements in physical fitness and walking function during rehabilitation. However, walking energy expenditure was statistically higher for participants with bilateral amputations relative to controls despite walking statistically slower, supporting previous literature that demonstrates increased energy expenditure is required when walking after bilateral lower-limb amputation [41-42].

This study only evaluated body composition during the first year after amputation, during which all servicemembers with amputations were actively engaged in rehabilitation. The changes we found may only be a trend, and data collected years following the completion of rehabilitation will better illustrate whether there is a potential for increased cardiovascular and metabolic concern for these patients. Future research may include a validated and reliable diet recall, which would assist in understanding the increase in fat mass not solely due to decreased exercise. 


\section{LIMITATIONS}

A limitation to the study is the small sample size. The dropout rate affected power to detect significant difference. Moreover, unilateral and bilateral participants may have had a difference of only 3 mo instead of 6 mo between baseline and follow-up visits because of baseline measurements occurring up to $12 \mathrm{wk}$ postamputation. Additionally, we disclosed the results of the baseline DXA scan to all participants, which may have influenced results at the 6 mo visit. Some participants noted that they did not like the results because it reminded them they had lost muscle mass or gained more fat than they would have liked, which they said motivated them to work harder. Also, we believe that some subjects did not return for follow-up visits because they did not like receiving the results of the scans. This disclosure may have contributed to the lack of significance in our study and the differences in results compared with other studies; however, the results were disclosed to all participants so comparisons between groups are valid. Finally, patients at this military facility receive prolonged rehabilitation when compared with civilian facilities. The patients were Active Duty servicemembers at the time of their injuries, so their care continues until they are able to return to duty or are medically discharged from the military. All participants in this study were still receiving care at the time of study completion, which is likely a longer rehabilitation program than patients outside this and other military facilities. Therefore, effect in body composition noted in participants undergoing more than $1 \mathrm{yr}$ of rehabilitation may not be generalizable to those receiving shorter durations of rehabilitation.

\section{CONCLUSIONS}

This study examined body composition and metabolic changes during the first year following unilateral and bilateral lower-limb traumatic amputation in military servicemembers. Weight gain was observed in both groups, with significant increases in fat and lean mass noted among the unilateral group in the first 9 mo postamputation. However, abdominal adiposity and increased BMI may increase risk for future development of cardiovascular disease and metabolic syndrome, similar to results found by other long-term studies of individuals with amputations. Future research should assess factors such as dietary intake and physical activity to better understand possibilities for intervention in this population.

\section{ACKNOWLEDGMENTS}

\section{Author Contributions:}

Study concept and design: A. M. Andrews, A. L. Pruziner. Acquisition of data: A. M. Andrews, A. L. Pruziner, A. D. Sanchez, C. S. Eckard.

Data analysis: A. M. Andrews, A. L. Pruziner.

Drafting of manuscript: A. M. Andrews, A. L. Pruziner,

A. D. Sanchez, C. S. Eckard.

Critical revision of manuscript for important intellectual content:

C. S. Eckard.

Financial Disclosures: The authors have declared that no competing interests exist.

Funding/Support: This material was based on work supported by the Military Amputee Research 15 Program (W81XWH-06-2-0073) and the Department of Defense-Department of Veterans Affairs Extremity Trauma and Amputation Center of Excellence (Public Law 110-417, National Defense Authorization Act 2009, Section 723).

Institutional Review: The study was approved by the Institutional Review Board at WRAMC in Washington, DC. All participants provided written, informed consent according to the guidelines of the Department of Clinical Investigation at WRAMC.

Participant Follow-Up: The authors have no plans to notify the study subjects of the publication of this article because of a lack of contact information.

Disclaimer: The views expressed in this article are those of the authors and do not necessarily reflect the official policy or position of the Department of the Army, Department of Defense, or U.S.

Government.

\section{REFERENCES}

1. Belavý DL, Miokovic T, Armbrecht G, Richardson CA, Rittweger J, Felsenberg D. Differential atrophy of the lower-limb musculature during prolonged bed-rest. Eur $\mathrm{J}$ Appl Physiol. 2009;107(4):489-99. [PMID:19680682] http://dx.doi.org/10.1007/s00421-009-1136-0

2. Krueger CA, Wenke JC, Ficke JR. Ten years at war: Comprehensive analysis of amputation trends. J Trauma Acute Care Surg. 2012;73(6 Suppl 5):S438-44. [PMID:23192067] http://dx.doi.org/10.1097/TA.0b013e318275469c

3. Miller M, Wong WK, Wu J, Cavenett S, Daniels L, Crotty M. Upper-arm anthropometry: An alternative indicator of nutritional health to body mass index in unilateral lowerextremity amputees? Arch Phys Med Rehabil. 2008; 89(10):2031-33. [PMID:18929034] http://dx.doi.org/10.1016/j.apmr.2008.03.025

4. Tugcu I, Safaz I, Yilmaz B, Göktepe AS, Taskaynatan MA, Yazicioglu K. Muscle strength and bone mineral density in 
mine victims with transtibial amputation. Prosthet Orthot Int. 2009;33(4):299-306. [PMID:19961291]

http://dx.doi.org/10.3109/03093640903214075

5. Renström P, Grimby G, Morelli B, Palmertz B. Thigh muscle atrophy in below-knee amputees. Scand J Rehabil Med Suppl. 1983;9:150-62. [PMID:6585937]

6. Sherk VD, Bemben MG, Bemben DA. Interlimb muscle and fat comparisons in persons with lower-limb amputation. Arch Phys Med Rehabil. 2010;91(7):1077-81. [PMID:20599046] http://dx.doi.org/10.1016/j.apmr.2010.04.008

7. Jaegers SM, Arendzen JH, de Jongh HJ. Changes in hip muscles after above-knee amputation. Clin Orthop Relat Res. 1995;(319):276-84. [PMID:7554640]

8. Schmalz T, Blumentritt S, Reimers CD. Selective thigh muscle atrophy in trans-tibial amputees: An ultrasonographic study. Arch Orthop Trauma Surg. 2001;121(6): 307-12. [PMID:11482460] http://dx.doi.org/10.1007/s004020000227

9. Fraisse N, Martinet N, Kpadonou TJ, Paysant J, Blum A, André JM. [Muscles of the below-knee amputees]. Ann Readapt Med Phys. 2008;51(3):218-27. French. [PMID:18358554] http://dx.doi.org/10.1016/j.annrmp.2008.01.012

10. Isakov E, Burger H, Gregoric M, Marincek C. Stump length as related to atrophy and strength of the thigh muscles in trans-tibial amputees. Prosthet Orthot Int. 1996; 20(2):96-100. [PMID:8876002]

11. Renström P, Grimby G, Larsson E. Thigh muscle strength in below-knee amputees. Scand J Rehabil Med Suppl. 1983;9:163-73. [PMID:6585938]

12. Moirenfeld I, Ayalon M, Ben-Sira D, Isakov E. Isokinetic strength and endurance of the knee extensors and flexors in trans-tibial amputees. Prosthet Orthot Int. 2000;24(3):221-25. [PMID:11195357] http://dx.doi.org/10.1080/03093640008726551

13. Sadeghi H, Allard P, Duhaime PM. Muscle power compensatory mechanisms in below-knee amputee gait. Am J Phys Med Rehabil. 2001;80(1):25-32. [PMID:11138951] http://dx.doi.org/10.1097/00002060-200101000-00007

14. Demling RH, DeSanti L. Involuntary weight loss and the nonhealing wound: The role of anabolic agents. Adv Wound Care. 1999;12(1 Suppl):1-14, quiz 15-16. [PMID:10326335]

15. Gorgey AS, Dudley GA. Skeletal muscle atrophy and increased intramuscular fat after incomplete spinal cord injury. Spinal Cord. 2007;45(4):304-9. [PMID:16940987]

16. Kurdibaylo SF. Obesity and metabolic disorders in adults with lower limb amputation. J Rehabil Res Dev. 1996; 33(4):387-94. [PMID:8895133]

17. Haboubi NH, Heelis M, Woodruff R, Al-Khawaja I. The effect of body weight and age on frequency of repairs in lower-limb prostheses. J Rehabil Res Dev. 2001;38(4): 375-77. [PMID:11563489]

18. Mueller C. Inflammation and malnutrition. Topics Clin Nutr. 2011;26(1):3-9.

http://dx.doi.org/10.1097/TIN.0b013e318209e38b

19. Kavalukas SL, Barbul A. Nutrition and wound healing: An update. Plast Reconstr Surg. 2011;127(Suppl 1):38S-43S.

[PMID:21200272]

http://dx.doi.org/10.1097/PRS.0b013e318201256c

20. Buckley S, Kudsk KA. Metabolic response to critical illness and injury. AACN Clin Issues Crit Care Nurs. 1994; 5(4):443-49. [PMID:7742135]

21. Demling RH. Nutrition, anabolism, and the wound healing process: An overview. Eplasty. 2009;9:e9.

[PMID:19274069]

22. Dekkers JC, van Wier MF, Hendriksen IJ, Twisk JW, van Mechelen W. Accuracy of self-reported body weight, height and waist circumference in a Dutch overweight working population. BMC Med Res Methodol. 2008;8:69. [PMID:18957077] http://dx.doi.org/10.1186/1471-2288-8-69

23. Bolton-Smith C, Woodward M, Tunstall-Pedoe H, Morrison C. Accuracy of the estimated prevalence of obesity from self reported height and weight in an adult Scottish population. J Epidemiol Community Health. 2000;54(2): 143-48. [PMID:10715748] http://dx.doi.org/10.1136/jech.54.2.143

24. Dhaliwal SS, Howat P, Bejoy T, Welborn TA. Self-reported weight and height for evaluating obesity control programs. Am J Health Behav. 2010;34(4):489-99.

[PMID:20218760]

http://dx.doi.org/10.5993/AJHB.34.4.10

25. Osterkamp LK. Current perspective on assessment of human body proportions of relevance to amputees. J Am Diet Assoc. 1995;95(2):215-18. [PMID:7852688] http://dx.doi.org/10.1016/S0002-8223(95)00050-X

26. Himes JH. New equation to estimate body mass index in amputees. J Am Diet Assoc. 1995;95(6):646.

[PMID:7759736] http://dx.doi.org/10.1016/S0002-8223(95)00175-1

27. Sun Q, van Dam RM, Spiegelman D, Heymsfield SB, Willett WC, Hu FB. Comparison of dual-energy x-ray absorptiometric and anthropometric measures of adiposity in relation to adiposity-related biologic factors. Am J Epidemiol. 2010;172(12):1442-54. [PMID:20952596]

http://dx.doi.org/10.1093/aje/kwq306

28. Going SB, Massett MP, Hall MC, Bare LA, Root PA, Williams DP, Lohman TG. Detection of small changes in body composition by dual-energy x-ray absorptiometry. Am J Clin Nutr. 1993;57(6):845-50. [PMID:8503351]

29. Glickman SG, Marn CS, Supiano MA, Dengel DR. Validity and reliability of dual-energy X-ray absorptiometry for the 
assessment of abdominal adiposity. J Appl Physiol. 2004; 97(2):509-14. [PMID:15075304]

http://dx.doi.org/10.1152/japplphysiol.01234.2003

30. Oxycon mobile device [Internet]. San Diego (CA): CareFusion; 2014 [cited 2014 May 11]. Available from: http://www.carefusion.com/medical-products/respiratory/ cardio-pulmonary-diagnostics/metabolic-carts-cpetnutrition/metabolic-carts/oxycon-mobile.aspx

31. Rosdahl H, Gullstrand L, Salier-Eriksson J, Johansson P, Schantz P. Evaluation of the Oxycon Mobile metabolic system against the Douglas bag method. Eur J Appl Physiol. 2010;109(2):159-71. [PMID:20043228] http://dx.doi.org/10.1007/s00421-009-1326-9

32. Trappe TA, Burd NA, Louis ES, Lee GA, Trappe SW. Influence of concurrent exercise or nutrition countermeasures on thigh and calf muscle size and function during 60 days of bed rest in women. Acta Physiol (Oxf). 2007; 191(2):147-59. [PMID:17655736] http://dx.doi.org/10.1111/j.1748-1716.2007.01728.x

33. Shahriar SH, Masumi M, Edjtehadi F, Soroush MR, Soveid M, Mousavi B. Cardiovascular risk factors among males with war-related bilateral lower limb amputation. Mil Med. 2009;174(10):1108-12. [PMID:19891226] http://dx.doi.org/10.7205/MILMED-D-00-0109

34. Gallagher D, Heymsfield SB, Heo M, Jebb SA, Murgatroyd PR, Sakamoto Y. Healthy percentage body fat ranges: An approach for developing guidelines based on body mass index. Am J Clin Nutr. 2000;72(3):694-701. [PMID:10966886]

35. Casanueva FF, Moreno B, Rodríguez-Azeredo R, Massien C, Conthe P, Formiguera X, Barrios V, Balkau B. Relationship of abdominal obesity with cardiovascular disease, diabetes and hyperlipidaemia in Spain. Clin Endocrinol (Oxf). 2010;73(1):35-40. [PMID:19832855]

36. Ito H, Nakasuga K, Ohshima A, Maruyama T, Kaji Y, Harada M, Fukunaga M, Jingu S, Sakamoto M. Detection of cardiovascular risk factors by indices of obesity obtained from anthropometry and dual-energy X-ray absorptiometry in Japanese individuals. Int J Obes Relat Metab Disord. 2003;27(2):232-37. [PMID:12587004]

http://dx.doi.org/10.1038/sj.ijo.802226
37. Naghii MR. The importance of body weight and weight management for military personnel. Mil Med. 2006;171(6): 550-55. [PMID:16808140]

38. Ricciardi R, Deuster PA, Talbot LA. Effects of gender and body adiposity on physiological responses to physical work while wearing body armor. Mil Med. 2007;172(7):743-48. [PMID:17691688] http://dx.doi.org/10.7205/MILMED.172.7.743

39. Jørgensen L, Jacobsen BK. Changes in muscle mass, fat mass, and bone mineral content in the legs after stroke: A 1 year prospective study. Bone. 2001;28(6):655-59. [PMID:11425655] http://dx.doi.org/10.1016/S8756-3282(01)00434-3

40. Naschitz JE, Lenger R. Why traumatic leg amputees are at increased risk for cardiovascular diseases. QJM. 2008; 101(4):251-59. [PMID:18281705] http://dx.doi.org/10.1093/qjmed/hcm131

41. Waters RL, Mulroy S. The energy expenditure of normal and pathologic gait. Gait Posture. 1999;9(3):207-31. [PMID:10575082] http://dx.doi.org/10.1016/S0966-6362(99)00009-0

42. Hoffman MD, Sheldahl LM, Buley KJ, Sandford PR. Physiological comparison of walking among bilateral aboveknee amputee and able-bodied subjects, and a model to account for the differences in metabolic cost. Arch Phys Med Rehabil. 1997;78(4):385-92. [PMID:9111458] http://dx.doi.org/10.1016/S0003-9993(97)90230-6

Submitted for publication February 13, 2014. Accepted in revised form March 31, 2015.

This article and any supplementary material should be cited as follows:

Eckard CS, Pruziner AL, Sanchez AD, Andrews AM. Metabolic and body composition changes in first year following traumatic amputation. J Rehabil Res Dev. 2015; 52(5):553-62.

http://dx.doi.org/10.1682/JRRD.2014.02.0044

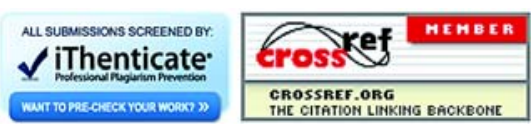

